\title{
Effect of Flame Retardants and 1\% Stabilizer on Burning and Melt Dripping Behaviour of PP Thermoplastic Polymers
}

\author{
Mastura Abdoalsalam A. Efhema ${ }^{1^{*}}$, Price B. Mottershead ${ }^{2}$

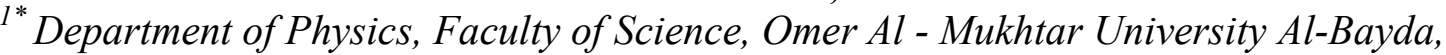 \\ Libya \\ .$^{2}$ Institution for Materials Properties Research and innovation Centre, UK
}

Received: 04 May 2019/ Accepted: 30 December 2019

Doi: https://doi.org/10.54172/mjsc.v34i4.141

\begin{abstract}
This study aimed to understand the mechanism of combining the action of different types of flame retardants (FR) on melting, flammability behaviour and burning behaviour, and its moderation of the Polypropylene (PP) polymer. PP Polymer was chosen to be blent in a twin-screw extruder with the flame retardants and an additive, which is a $1 \%$ Stabilizer, to investigate Polypropylene's melting, flammability and burning moderation in order to reduce it. Burning and flammability behaviour test conditions, which are known as UL49 vertical and horizontal burning tests, were applied in this study. The flame was applied for 10 seconds and the length of time that the sample burned was measured. The flame was reapplied $10 \mathrm{~mm}$ below the burned edge of the sample for a further 10 seconds. The length of time the sample burned for a second time was measured. The melting, dripping, and burning behaviour was recorded using high-speed video. These PP Polymer samples behave very differently in terms of upward flame spread. The study also indicates that the melting behaviour of thermoplastic materials is an important characteristic in fires which should be taken into account in the development of models, in particular for upward flame spread models. To study melt dripping behaviour, a burning methodology was developed. The results from these experiments have been analyzed to draw a relationship between melt dripping and burning behaviour. Most of the previous work on melt and dripping behaviour was concentrated on the study of fire operating conditions and modelling of the thermal process, however, no work has been reported on the quantitative relationship between melt and burning behaviour of thermoplastic polymers.
\end{abstract}

Keywords: Flammability, PP Polymer, Flame retardants, Thermoplastic, Burning, Stabilize.

\section{INTRODUCTION}

The present study is part of a larger project exploring the production of fire retardant synthetic nano/micro composite fibres. This work concentrated on Polypropylene also known as Polypropylene (PP) which is a useful commodity polymer mainly used in clothing, furniture, floor coverings, geotextiles, medical, and automotive applications, due to its low cost, lightweight, good mechanical properties and low reactivity towards other chemicals.
Polypropylene (PP) had higher values for tensile strength at break. Polypropylene polymer degradation occurs at high temperatures. The Polypropylene polymer (PP) melting temperature is $174^{\circ} \mathrm{C}$ if pp is $100 \%$ isotactic, and the temperature of the glass transition of pp polymer is $-17^{\circ} \mathrm{C}$. The main advantage is that PP is an addition polymer made from the monomer propylene, causing it to be unusually resistant to many chemical solvents, acids, and bases. However, being a wholly aliphatic hydrocarbon structure, it burns 
very rapidly with a relatively smoke-free flame and without leaving any char residue (Zhu et al., 2001). Lack of polar groups in the structure makes it difficult to react with reactive flame retardants. Additive flame retardants if used, are needed in large amounts $(>20 \% \mathrm{w} / \mathrm{w})$ to provide the required fire protection to products(Zhang et al., 2005). This flame retardancy effect increases with increasing irradiation and vanishes with decreasing irradiation (Qin et al., 2005). However, such high levels of additives cause polymer processing problems, in particular for their extrusion into thin films or fibres. The flame retardancy is sensitive to modification of the flame retardant, the use of synergists/adjuvants, and changes to the polymeric material. A detailed understanding facilitates the launch of tailored and targeted development (Morgan \& Wilkie, 2007). Flammability tests still require some amount of conventional flame retardants. It must be noted, however, that with this approach of using flame retardants as additives, the polymer content in the formulation is reduced compared to the unmodified polymer. In our earlier publications, we have demonstrated that nanoclays can be nanodispersed in polypropylene with a proper choice of compatibilizer, and the compounded polymer can be extruded into fibres (Gilman, 2007; Qin et al., 2005). Nanoclays, although increasing the thermal stability of polypropylene and helping in char formation (Xie et al., 2001), they do not reduce the flammability of PP fibres to a large extent (Qin et al., 2005). Clay, Nano clay, and a small amount of flame retardant $(5 \%)$ when added together to PP containing certain compatibilizers, the extruded fibres could be self-extinguished. In our previous work, we have only used ammonium polyphosphate (Qin et al., 2005) whereas, in this study, we use different phosphorus. The main aim of this work is to understand the mechanism of combining the action of different types of flame retardants on thermal stability and flammability of PP. Several polypropylene samples containing compatibilizer, clay, stabilizer, and different flame retardants have been compounded in a twin-screw extruder.

\section{MATERIALS AND METHODS}

The following materials were obtained from commercial sources: the seven different thermoplastic Polypropylene polymers (PP). Samples are tested after blended with UVStabilizer (Nor) and Flame Retardants.

Polymer Preparation: The 7 polypropylene samples composition (wt \%) and additives were blended with 1\% Stabilizer (Nor 116), and 5\% FR as shown in Table 1. For Limiting oxygen index LOI; (LOI schematic as seen below) and burning tests, coarse monofilaments (strands) were blended to the PP wt. \%, stabilizer 1 wt. \%, and FR 5 wt. \% (Table 1). However, the nanoclays which could be used (Cloisite 20A, and Southern Clay Products, USA) are montmorillonite clay modified with dimethyl and dihydrogenated tallow quaternary ammonium chloride. This modified clay was chosen because of its nonpolar alkyl substituents. A Thermoelectron Prism EuroLab 16 twin-screw extruder with a temperature profile over six heating zones between 179-1900C was used for compounding. The polymer samples (diameter $1.8 \pm 0.2 \mathrm{~mm})$ were collected before pelletizing.

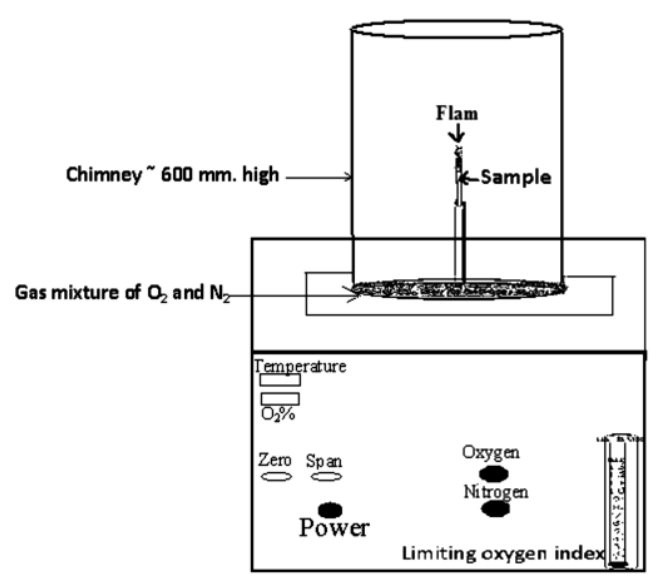

The schematic of the (LO1) tests 
Table (1). Mass percentages of various components in the formulations where Stabilizer 1\% is NOR 116.

\begin{tabular}{|c|c|c|c|c|}
\hline Sample5(\%) & $p p \%$ & $\begin{array}{l}\text { Clay } \\
3 \%\end{array}$ & Graft 1\% & $F R$ \\
\hline $\begin{array}{l}\text { 1- PP-Nor } \\
116\end{array}$ & 100 & -- & -- & -- \\
\hline $\begin{array}{l}\text { 2- PP-APP } \\
107\end{array}$ & 96 & 107 & $\begin{array}{l}\text { Polybond } \\
\text { (pb) }\end{array}$ & -- \\
\hline $\begin{array}{l}\text { 3- PP-NOR- } \\
N H\end{array}$ & 91 & 107 & Polybond & APP \\
\hline 4- PP FR 107 & 91 & 107 & Polybond & ${ }^{1} \mathrm{FR} 245$ \\
\hline $\begin{array}{l}\text { 5- PP } \\
\text { Amgard } 107\end{array}$ & 91 & 107 & Polybond & $\begin{array}{l}\text { Amgrad } \\
\mathrm{NH}\end{array}$ \\
\hline 6- РP 3OB & 96 & $3 \mathrm{OB}$ & Polybond & -- \\
\hline $\begin{array}{l}\text { 7- PP APP } \\
30 B\end{array}$ & 92 & $3 \mathrm{OB}$ & -- & APP \\
\hline \multicolumn{5}{|c|}{$\begin{array}{l}\text { 3OB } \\
\text { Note: }{ }^{1} F R=A P P, N H, F R 245 \text {, also PP-NOR-NH is PP } \\
\text { 107,FR372 or FR245 }\end{array}$} \\
\hline
\end{tabular}

Characterisation and Testing: Halogenated flame retardants FR245 and 372 had little effect on the rate of decomposition (Efhma, 2018).The addition of clay with or without flame retardants increased the thermal stability of all samples as indicated by respective DTG (The differential thermal analysis (DTA) was performed on a TA instruments SDT 2960 simultaneous TGA instrument under flowing air) maximum temperature values (Efhma, 2018). Clay, together with melamine phosphate, had no further effect (Schartel et al., 2006; Xie et al., 2001) on the flame retarded sample or the incompatibility of melamine phosphate with the organically modified clay. This has also been observed in my previous study (Efhma, 2018). Thus, the addition of clay together with conventional flame retardants enhances both the overall melt and burn with flaming drips during UL-94 testing. UL-94 test of Flame spread and burning behaviour and Flammability in horizontal and vertical modes as seen in fig.1.

The differences are due to the effect of different flame retardants on the dispersion of the clay (Morgan \& Wilkie, 2007; Xie et al., 2001) They also reduce the rate of gas escape from polymer melt affecting the viscosity and hence, prevents the melt dripping of the polymer during vertical UL-94 testing and holds the polymer together (Hu \& Song, 2007). As can be seen from Figure 1 FR245 in PP helps samples self-extinguish (SE) i.e. flameout (FO).

Flame spread and burning behaviour: Flammability of the compounded polymer strands was studied using UL-94 testing (Figure 1 a, b, c, d, e, f, and g 1,2), igniting the sample and recording times taken to reach 50 (T1) (Table 2 and 3) and $100 \mathrm{~mm}$ (T2) marks and to extinguish (flameout, FO) in both horizontal and vertical modes. Selected images are shown in Figure 1 and Table 2. In the horizontal mode the PP sample melted and burned with flaming drips. In both horizontal and vertical modes, all samples with flame retardants and no clay, burnt completely (Fig. $1 \mathrm{~b}$ and e), which is not unexpected, given the low levels $(5 \%)$ of flame retardants used here. However, the flame spread was low as seen in Table 3. On addition of clay to the compounded polymer, a change in burning behaviour was observed and recorded, e.g. samples self-extinguished (SE), except for the one containing a melamine phosphate sample PP-NOR-NH (see Table 2 and 3, also Figure 1f). In some samples (e.g. containing APP) the flame flickered, which was probably due to poor dispersion of the flame retardant in the polymer (Hu \& Song, 2007).

The UL-94 vertical burning test (Morgan \& Wilkie, 2007; Zhu et al., 2001) is a widely used fire test for industrial polymeric materials and products. The flaming time and the dripping phenomena are two observed test results that have been reported for many materials. Good flame retardant formulations that gift polymers with short flaming times and non-dripping are also screened by the two test results. However, the test results have generally no use for the theoretical understanding of the advantages of the good formulations because the results are not related to the fire dynamics. Especially, the ignition process, the burning rate, the flame 
spread rate, and the rate of dripping for polymers in the UL-94 vertical burning test as they have not been focused on. In fact, although numerous good flame retardant formulations for polymers are often reported, few fundamental studies on the basics of the fire dynamics of the test have been conducted.
Furthermore, the absence of the fire dynamic behaviours of polymers in the UL-94 test also makes it difficult to correlate the UL-94 test with other fire tests such as the cone calorimeter test, in which more scientific parameters such as heat release rate and mass loss rate are presented.
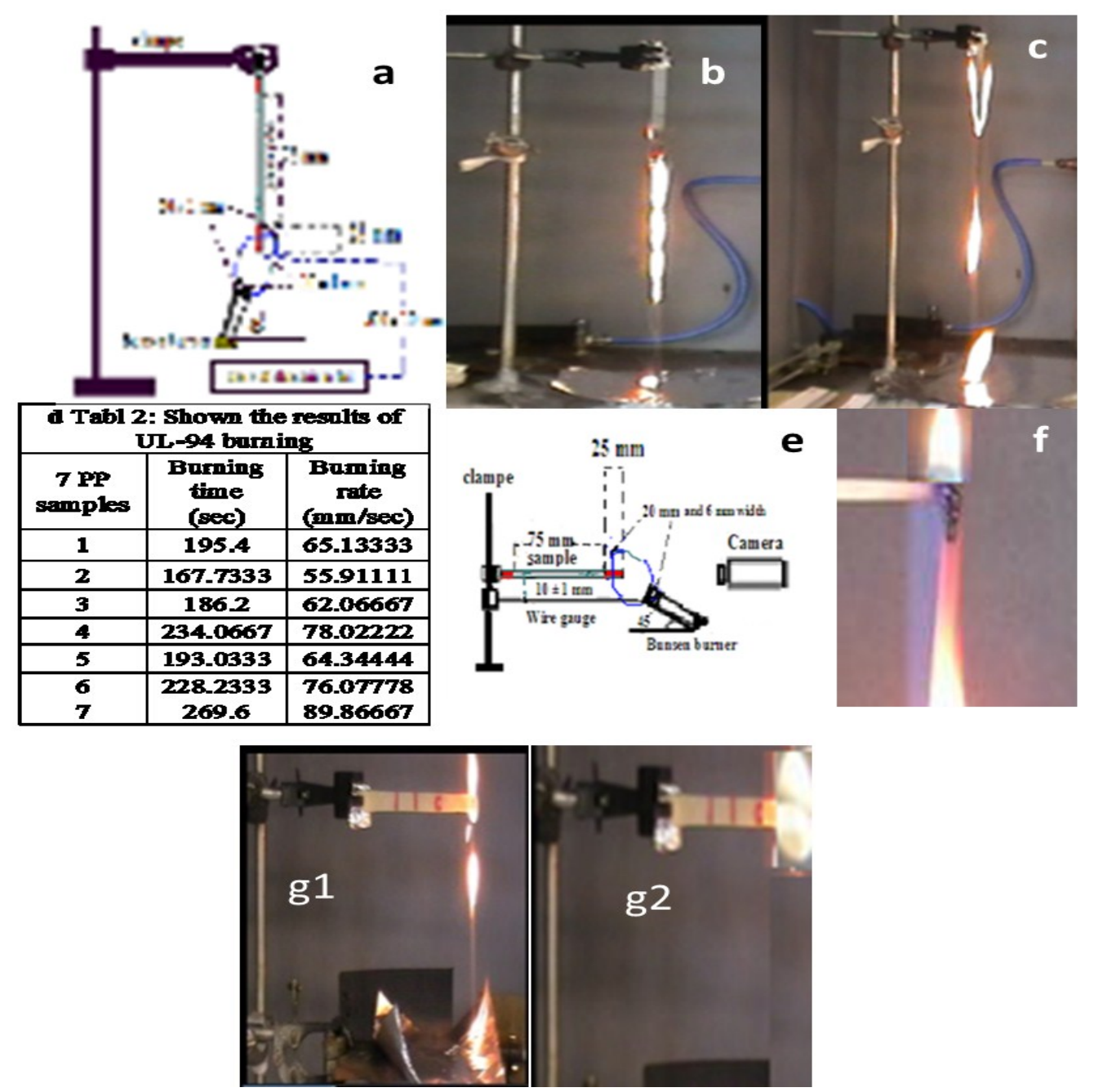

Figure: (1). Summery of the results of UL-94 test (both horizontal and vertical modes) of 7 PP samples composition (ww\%) blended with 1\% Stabiliser, 1\% Graft, 3\% Clay and 5\% FR, as seen in Table 1, their size is $125 \mathrm{mmx} 10 \mathrm{mmx} 3$ mm thick.

Note: $\mathrm{T} 1=$ time to $50 \mathrm{~mm} ; \mathrm{T} 2=$ time to $100 \mathrm{~mm} ; \mathrm{FO}=$ flameout time; $\mathrm{M}=$ melting; $\mathrm{BD}=$ burning drips; $\mathrm{LBD}=$ low burning drips $\mathrm{SE}=$ self-extinguished; $*$ = burnt completely.

In the vertical mode, burning of the control sample was more vigorous with melting drips (see Tables 2 and 3 and Figures $1 b$ and c). With flame retardants, there was not much effect on burning, except for the sample containing FR372 which self-extinguished
(Figure 1g). The clay presence in PP reduced melt-dripping e.g. sample PP-NOR-NH sample 3- (Fig.1e), but had minimal effect on burning, however, with Clay no FR, FR 245, Amgrad NH, and FR APP respectively (Tables 1 and 2), the effect was promising and the 
samples which self-extinguished were samples 2, 4, 5 and 7 (Table 2) also Figure 1g, furthermore, the Melting behaviour and Physics properties were recorded as seen in Fig.1.

\section{Melting behaviour and Physical properties:}

In the UL94 vertical burning test, the mass of the first drop increases with the first dripping time. The high dripping frequency and the small size and mass of PP agree with the observation that in the UL94 vertical burning test the rate of dripping decreases while the size and mass of drops increase (fire drip, 1996). These results and more can be seen in Table 3 by recording the times and masses for the first dripping. Furthermore, for PP it can be found that the first dripping time does not significantly increase with the specimen thickness.

Table (3). Record the times and masses for the first dripping to investigate the melting behaviour

\begin{tabular}{cllllllll}
\hline \hline \multicolumn{3}{c}{ Specimen A } & \multicolumn{5}{c}{ Specimen B } \\
\hline Polymers & $\begin{array}{c}\text { Thickness } \\
(\mathrm{mm})\end{array}$ & $\mathrm{TD}(\mathrm{s})$ & $\mathrm{MD}(\mathrm{g})$ & $\mathrm{TD}(\mathrm{s})$ & $\mathrm{MD}(\mathrm{g})$ & ATD $(\mathrm{s})$ & AMD $(\mathrm{g})$ & $\begin{array}{l}\text { ADD } \\
(\mathrm{mm})\end{array}$ \\
\hline & 2 & 13 & 0.0158 & 12 & 0.0186 & 12 & 0.0172 & 3.3 \\
& 4 & 15 & 0.0146 & 14 & 0.0287 & 14 & 0.0217 & 3.6 \\
PP & 6 & 16 & 0.0078 & 15 & 0.0147 & 15 & 0.0113 & 2.9 \\
& 8 & 14 & 0.0067 & 16 & 0.0012 & 15 & 150.0040 & 2.0 \\
& 10 & 14 & 0.0086 & 15 & 0.0110 & 15 & 0.0098 & 2.8 \\
\hline \hline
\end{tabular}

Note: TD, the time of the first dripping; MD, the mass of the first drop; ATD, average time of the first dripping;

AMD, average mass of first drops; ADD, average diameter of first drops.

It seems that the PP mass of the first drop has a minor increase with the specimen thickness. This finding is related to the decomposition mechanism and dripping of PP polymers.

As thick specimens have a larger crosssectional area and larger melt strength than thin specimens, they can undergo longer times or larger melt mass weight without break. However, the dripping of PP is small-size dripping. The decomposition significantly reduces the molecular weight, followed by the easy flowing of polymer melts. The melting wax can flow over surfaces of the specimen and drip.

Flame retardant mechanism: Polypropylene (PP) undergoes decomposition via random chain scission involving the formation of some unsaturated end groups, e.g. $-\mathrm{C}(\mathrm{CH} 3)=\mathrm{CH} 2$ (Xie et al., 2001). Accompanying oxidation via hydroperoxide formation yields further scission products comprising alcohols, ketones, and acidic functionalities. There is little evidence of any tendency to cross-link and form char during this process, thereby presenting a significant flame retardant challenge (Gilman, 2007). It can be seen from the discussion in previous sections that the molecular weight decreases, followed by easy flowing of polymer melts, which was in PP containing PPg-MA. It has been reported in the literature (Council, 1977; Hu \& Song, 2007) that thermal degradation of organoclays can create acidic sites on the clay, which catalyse the initial decomposition stages of a polymer, resulting in a lowering of ignition time and LOI values for many polymer-nanocomposite samples (Efhma, 2018). The acidic sites, however, catalyse formation of a protective surface coating on the surface of polymer, which acts as a thermal barrier leading to delay of thermooxidative degradation. In some cases, clays can also catalyse dehydrogenation and crosslinking of polymer chains, thus reducing combustion.

Phosphorus- and nitrogen-containing flame retardants acting in condensed phase produce char, which acts as a thermal barrier for the decomposing polypropylene. There is no 
evidence of chemical interaction between the flame retardants and PP in this work or from the previous study (Efhma, 2018) and the literature. Halogenated flame retardants acting in the vapour phase help in removing active free radicals from the combustion zone, thus reducing the combustion of the polymer. In PPPB-clay-FR samples, char formation has been generally enhanced for both phosphorus- and halogen-containing flame retardants, with the former yielding greater increases. (Hu \& Song, 2007) has suggested that in case of phosphorus-containing flame retardants, phosphoric acid released can react with the quaternary ammonium salt of the Nanoclay (Xie et al., 2001), thus creating acidic sites on the clay as observed by (Qin et al., 2005), which enhance char formation. Similarly, HB released from $\mathrm{PB}$ flame retardants can react with the quaternary ammonium salt of the clay (Hu \& Song, 2007). Although supporting this mechanism, we have not found any evidence of these reactions in this work.

\section{CONCLUSIONS}

The dispersion of nanoclay can be improved by compounding polymer-clay samples (Hu \& Song, 2007) and by adding compatibilizer. LOI values are not changed significantly following the addition of clay and even in the presence of other flame retardants (Mastura A. Efhma, 2018). However, the presence of nanoclay alone changes the thermal stability and burning behaviour of the polypropylene. With additional flame retardant presence, the polymer can show self-extinguishing properties as seen in sample 4 .

The effect of different flame retardant types on the thermal stability, flammability, and the char formation tendency of optical micrographs of tape samples showing the effect of Polybond $(\mathrm{Pb})$ on clay dispersion (Efhma, 2018) which effected on flammability behaviour and dripping polypropylene (PP) is studied. PP, compatibilizer, Clay, stabiliser, and different flame retardants have been compounded in a twin-screw extruder to produce polymers with improved thermal and flame retardant properties. Thermal analysis has been used to study the thermal properties, and a slightly modified UL-94 test for testing the flammability of the samples. All flame retardants acting in the condensed phase (phosphorus- and nitrogen-containing) (Xie et al., 2001) lowered the rate of decomposition, whereas halogenated flame retardants had a little effect (Efhma, 2018). All PP samples with flame retardants and no clay, burnt completely, which is not unexpected, given the low levels (5\%) of flame retardants used here. However, the flame spread was low. Flammability behaviour testes using UL-94 were carried out to measure flammability properties and have been examined with digital images. Also, both flammability and melt dripping behaviour of burning polymers were measured by using the UL-94 test. However, the dripping of PP is small-size dripping. The decomposition significantly reduces the molecular weight, followed by the easy flowing of polymer melts. The melting wax can flow over surfaces of the specimen and drip. Thus, it is expected that the small-size dripping is independent of the crosssectional area of the specimen, that is, the first dripping time or the mass of the first drop has little to do with the thickness of the specimen.

Outcome and future work: Nanocomposites have suggested that by the addition of just a small quantity $(<5 \%)$ of organically modified layered silicate nanoclay (montmorillonite) (Morgan \& Wilkie, 2007) to a PP polymer matrix could enhance many of the properties of that polymer (Efhma, 2018), including the fire performance (Beyler \& Hirschler, 2002). We watched the effect of flame retardancy, FR and additives on the Polymers burning behaviors, Chemical, and Physical properties, and then dripping to try to stop the fire and potentially save lives (Efhma, 2018). Therefore it's very important to collect and record all the results related to these aims and more for future studies of flammability behaviour and dripping. 


\section{ACKNOWLEDGEMENTS}

I wish to thank the Engineering and Physical Sciences Research Council (EAPSR) and the Ministry of Defence, UK, for funding; and Rhodia Consumers Specialities Ltd and Camira Ltd., UK for their collaboration and advice

\section{REFERENCES}

Beyler, C. L., \& Hirschler, M. M. (2002). Thermal decomposition of polymers. SFPE handbook of fire protection engineering, 2 .

Council, N. R. (1977). Materials: state of the art (Vol. 1). National Academies .

Efhma A.,Mastura (2018). Effect of Flame Retardants and $1 \%$ Stabilizer on Burning, Flammability Behaviour, and Thermal Decomposition Properties Via Polypropylene Material Treatment.; AlMukhtar Journal of Sciences 33 (2): 119-125, 2018

Gilman, J. W. (2007). Flame retardant mechanism of polymer-clay nanocomposites. Flame retardant polymer nanocomposites, 67-87 .

Hu, Y., \& Song, L. (2007). Nanocomposites with halogen and nonintumescent phosphorus flame retardant additives. Flame Retardant Polymer Nanocomposites; Morgan, AB, Wilkie ، $C A, E d s, 191-234$.

Morgan, A. B., \& Wilkie, C. A. (2007). Flame retardant polymer nanocomposites. John Wiley \& Sons .

Qin, H., Zhang, S., Zhao, C., Hu, G., \& Yang, M. (2005). Flame retardant mechanism of polymer/clay nanocomposites based on polypropylene. Polymer, 46(19), 8386-8395.
Schartel, B., Bartholmai, M., \& Knoll, U. (2006). Some comments on the main fire retardancy mechanisms in polymer nanocomposites. Polymers for Advanced technologies, 17(9 - 10), 772-777.

Xie, W., Gao, Z., Pan, W.-P., Hunter, D., Singh, A., \& Vaia, R. (2001). Thermal degradation chemistry of alkyl quaternary ammonium montmorillonite. Chemistry of materials, 13(9), 29792990 .

Zhang, X., Guo, F., Chen, J., Wang, G., \& Liu, H. (2005). Investigation of interfacial modification for flame retardant ethylene vinyl acetate copolymer/alumina trihydrate nanocomposites. Polymer Degradation and Stability, 87(3), 411-418.

Zhu, J., Uhl, F. M., Morgan, A. B., \& Wilkie, C. A. (2001). Studies on the mechanism by which the formation of nanocomposites enhances thermal stability. Chemistry of materials, 13(12), 4649-4654 . 


\section{تأثير مثبطات اللهب وعامل مثبث 1\% على سلوك الاحتراق والأويان التنقيطي على بوليمر البولي برويلين الملان حرارياً \\ مستورة عبد السلام افحيمه 1"وبرايس ب. موتترهيد2

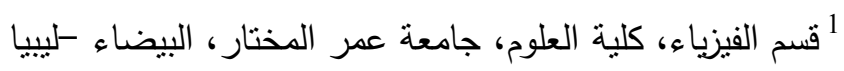

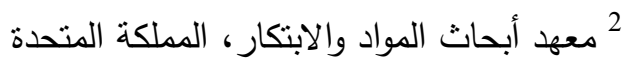

تاريخ الاستلام: 15 مايو 2017 / تاريخ القبول: 4 أغسطس 2018 https://doi.org/10.54172/mjsc.v34i4.141:Doi

المستخلص : تهدف هذه الدراسة إلى فهم آلية الجمع بين عمل أنواع مختلفة من مثبطات اللهب (FR) flame retardants) على

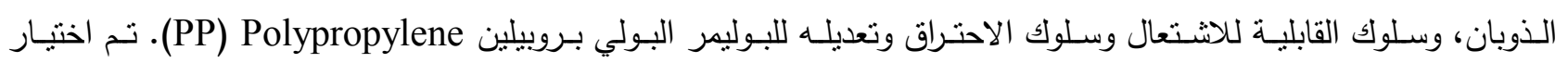

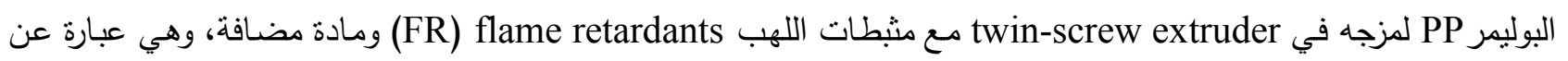

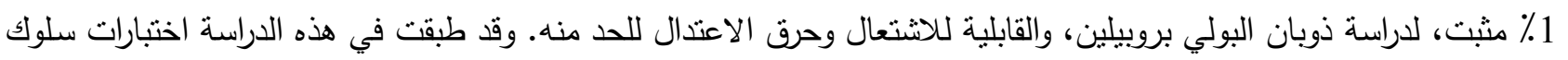

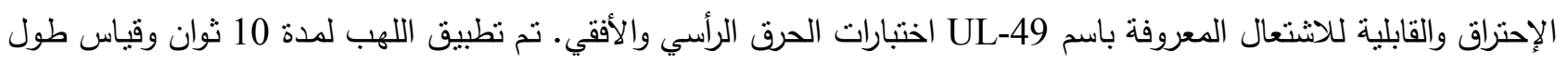

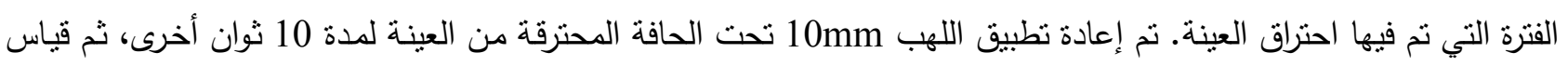

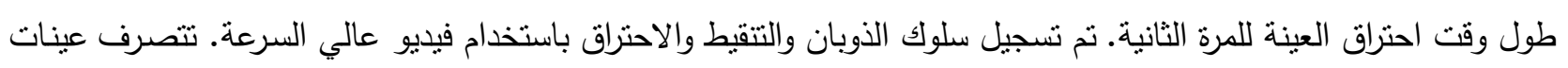
البولي بروبيلين هذه بشكل مختلف جداً من حيث انتشار اللهب التصاعدي. وتتشبر الدراسة أيضا إلى إن السلوك الذائب للدائن

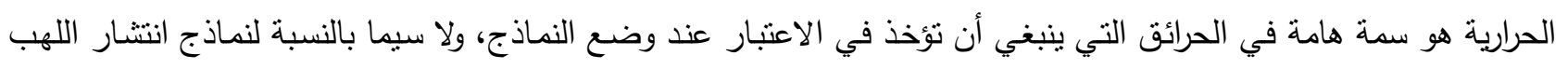

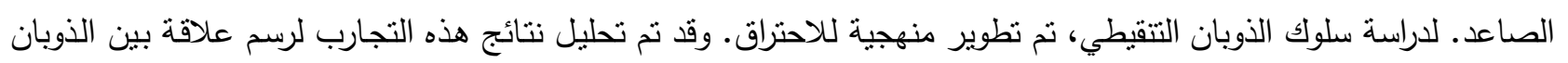

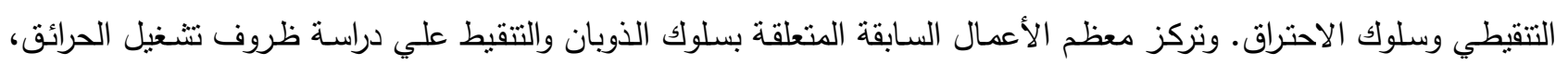
ونمذجـة العمليـة الحراريـة، غير إنـه لم يتم تسجيل أى عمل بشـان العلاقة الكميـة بين سلوك الذوبان والاحتراق في البوليمرات الحرارية. الكلمات المفتاحية: الاشتعال، بوليمر البولي بروبيلين، مثبطات اللهب، الاحتراق، تثبيت. 